\title{
Migraciones, derechos humanos y vulnerabilidad
}

\author{
Carlos Arce Jiménez
}

Resumen: Los objetivos de este artículo son analizar desde una perspectiva multidisciplinar los retos de la movilidad humana en la era de la globalización, las vulneraciones de Derechos Humanos derivadas de las disfunciones de los cauces por los que debe desenvolverse y apuntar alternativas a este contexto. Indagamos en las causas de las migraciones contemporáneas, prestando especial atención al concepto de vulnerabilidad, a los conflictos y a los espacios de vulneración generalizada de los Derechos Humanos. Se realiza una revisión crítica de los instrumentos políticos-jurídicos que regulan a nivel global y regional la protección internacional y la libertad de circulación que deberían facilitar una movilidad humana por vías legales y seguras, y las vulneraciones de derechos en los flujos migratorios en tránsito y en frontera.

Palabras clave: ciudadanía, conflictos, derechos humanos, fronteras, globalización, migraciones, vulnerabilidad.

Fecha de recepción: 24 de septiembre de 2017.

Fecha de admisión: 25 de octubre de 2017.

\section{Migrations, human rights and vulnerability}

Abstract: The objectives of this article are to analyze from a multidisciplinary perspective the challenges of the human mobility in the age of globalization, the infringement of Human Rights derived from the malfunctions of the channels through which it must disentangle, and to point out alternatives to this context.

\section{Migrations, droits del'Hommeetvulnérabilité}

Résumé: Les objectifs de cetarticle sontd'analyser depuis une perspective multidisciplinaire les défis de la mobilité humaine en cette ère de la mondialisation, les vulnérations des droits del'Homme, dérivés des disfonctionnements des voies à travers lesquelles elles doivent être résolves et montrer quelques alternatives 
We delve into the causes of contemporary migrations, paying special attention to the concept of vulnerability, to the conflicts, and to the spaces of generalized infringement of Human Rights. A critical revision is carried out of the politics-juridical instruments that, at a global and regional level, regulate the freedom of circulation that should facilitate a human mobility through legal and safe channels, and the infringements of the rights in the migratory streams while in transit and at the frontier.

Key words: Citizenship, conflicts, Human Rights, frontiers, globalization, migrations, vulnerability. à ce contexte. Nous nous interrogeons sur les causes des migrations contemporaines, en accordant une attention particulière au concept de vulnérabilité, aux conflits et aux espaces de vulnération généralisée des Droits de l'Homme. Nous réalisons une révision critique des instruments politico-juridiques qui régulent, au niveau global et régional, la protection internationale et la liberté de circulation qui devraient faciliter une mobilité humaine par des voies légales et sûres, ainsi que les vulnérations des droits dans les flux migratoires en transit et à la frontière.

Mots clé: Citoyenneté, conflits, Droits de l'Homme, frontières, mondialisation, migrations, vulnérabilité.

\section{Causas y procesos de las migraciones en la era de la globalización}

\section{I.I. La mejora de las condiciones de vida como factor impulsor de la movilidad humana}

El actual contexto migratorio es una etapa más dentro de un proceso histórico continuado. Múltiples causas han impulsado la movilidad humana a lo largo de los tiempos, pero hay un factor constante: la mejora de las condiciones de vida. Las migraciones contemporáneas no son una excepción. Desde que, a finales del siglo XX, emergió el proceso globalizador, la transnacionalización de las relaciones humanas genera un contexto en teoría idóneo para la movilidad, donde podría pensarse que las motivaciones de los flujos migratorios no necesariamente tendrían que estar vinculadas con una búsqueda de la mejora de las condiciones de vida más básicas. Sin embargo, cuando analizamos las migraciones actuales, emergen esas atávicas motivaciones de búsqueda de parámetros esenciales para el desarrollo de una vida digna.

Dentro de la búsqueda de mejores condiciones de vida, sigue teniendo prevalencia el «efecto expulsión» sobre el "efecto llamada». La pobreza, la falta de expectativas económico-laborales, la inseguridad ciudadana, los conflictos armados, el 
deterioro ambiental... en los países de origen de las personas migrantes, tienen una incidencia más relevante que los atractivos del lugar del destino. Esta premisa tiene relevancia a la hora de configurar el cómo de los procesos migratorios en la era de la globalización, y de poder entender por qué estos son un territorio abonado para la vulnerabilidad y las vulneraciones de derechos.

\section{I.2. Vulnerabilidad y migraciones}

Para acercarnos al concepto vulnerabilidad, su impacto en los derechos humanos en general, $y$ en la movilidad humana en particular, es de especial interés el Informe sobre Desarrollo Humano 2014 del Programa de Naciones Unidas para el Desarrollo (PNUD), titulado Sostener el progreso humano: reducir vulnerabilidades y construir resiliencia. Define vulnerabilidad como la «erosión de las capacidades y opciones de las personas» (PNUD, 2014:1); lo que se puede traducir en el lenguaje de los derechos como un contexto formal y/o material donde se cuestiona la titularidad y ejercicio de los derechos humanos de un colectivo determinado.

Puede señalarse la pobreza como el principal factor de vulnerabilidad de amplios segmentos de población. En los últimos años se han construido herramientas de medición de las situaciones de pobreza que permiten calibrar la influencia de las mismas en la titularidad efectiva de derechos. Uno de ellos es el índice de pobreza multidimensional ${ }^{1}$ (IPM), que tiene en cuenta dimensiones que van más allá del bajo nivel de renta. ${ }^{2}$

El PNUD destaca que, en el año 2014, unos 2.200 millones de personas se encontraban en situación de pobreza multidimensional o muy cerca ella (más del $30 \%$ de la población mundial). Otras cifras significativas son: casi el $80 \%$ de la población mundial carece de protección social integral, el 12\% sufre hambre crónica, hay 1.500 millones trabajadores con empleos precarios (la mitad de la fuerza laboral del planeta) y el $75 \%$ de la pobreza se concentra en las zonas rurales. También es

1 Concepto elaborado por el PNUD. Disponible en: http://hdr.undp.org/es/content/ indice-de-pobreza-multidimensional-ipm

${ }^{2}$ El IPM atiende las dimensiones que configuran el índice de desarrollo humano (IDH), que son: tener una vida larga y saludable, adquirir conocimientos y disfrutar de un nivel de vida digno. Se han ido incorporando nuevas variables como las desigualdades (de género, p.ej.), seguridad humana, empoderamiento... que ahondan en la perspectiva multifocal de la pobreza como factor clave en la titularidad y ejercicio de los derechos humanos. Disponible en: http://hdr.undp.org/es/content/ el-\%C3\%ADndice-de-desarrollo-humano-idh 
revelador que las nuevas amenazas globales se ceban en las zonas más empobrecidas de la Tierra. El informe pone de relieve que, en el periodo 2000-2012, más de 200 millones de personas al año se vieron afectadas por desastres naturales vinculados en gran medida al cambio climático, la mayoría de ellas en países en desarrollo. La vulnerabilidad vinculada a la pobreza hace diana preferente de los nuevos riesgos para la vigencia efectiva de los derechos humanos a las zonas geográficas y colectivos sociales que la sufren (PNUD, 2014).

Estas reflexiones tienen como objeto enmarcar las condiciones de pobreza de algunas regiones del planeta y la vulnerabilidad que las acompañan como causas de los flujos migratorios contemporáneos. Como última cuestión inicial hay que señalar que se suele distinguir entre movimientos migratorios por razones económico-laborales y aquellos vinculados a situaciones de conflicto y/o persecución. Sin embargo, es cada vez más difícil establecer una diferenciación estricta entre ambas categorías, consolidándose el concepto de flujos mixtos, "movimientos de población complejos, que incluyen a refugiados, solicitantes de asilo, migrantes económicos y otros migrantes» (OIM, 2009:1). Sin perderlo de vista, el uso de esa doble terminología será inevitable para demostrar nuestra tesis de que el «efecto expulsión» es el factor determinante de las causas y procesos de la movilidad humana en la era de la globalización.

Las estadísticas sobre la movilidad humana corroboran que la mejora de las condiciones de vida sigue siendo el principal motor de los flujos migratorios. El Informe sobre migraciones internacionales 2015 de la División de Población del Departamento de Asuntos Económicos y Sociales (ONU) señala que, en el periodo 2000-2015, las migraciones internacionales ascendieron a 71 millones de personas, de las cuales 57 millones tuvieron como destino países de altos ingresos ${ }^{3}$ (81\% del total). En estos países, los flujos migratorios aumentaron más de un 2,5\% anual durante esos 15 años, mientras que en los de ingresos medianos o bajos el incremento fue inferior (1,5\% en los primeros y el 1,2\% en los segundos) (ONU, 2016).

\footnotetext{
${ }^{3}$ Se considera que un país es de ingresos altos cuando su ingreso nacional bruto (INB) per capita es igual o superior a los 11.906 US\$. Países de ingresos bajos serían aquellos cuyo INB es inferior a los 975 US\$, los países de ingresos medianos altos tienen un INB entre 3.856 US $\$$ y 11.905 US\$) y en los de ingresos medianos bajos el INB se sitúa entre 976 US\$ y 3.855 US\$). Banco Mundial: http:// datos.bancomundial.org/quienes-somos/clasificacion-paises
} 


\section{I.3. La opción de la movilidad como privilegio}

Otros datos reveladores del Informe sobre migraciones internacionales 2015 son que, en el año 2015 , el $65 \%$ de los migrantes a nivel mundial provenían de países de ingresos medios, el $25 \%$ de países de ingresos altos y tan sólo el $10 \%$ de países de ingresos bajos. Las estadísticas sobre el destino también dan información clave: el $77 \%$ de los migrantes nacionales de Estados de ingresos medios residen en Estados de ingresos altos, mientras que los provenientes de los países de ingresos bajos se dirigen prioritariamente a Estados de ingresos medios (un 57\%, frente a un $19 \%$ que se ubican en países de altos ingresos).

Se podría entender que esas cifras cuestionan la idea de que el motor principal de las migraciones sea la mejora de las condiciones de vida. Que los países con un mayor bienestar sean los destinatarios preferentes de los flujos migratorios refrendaría esa afirmación. Pero se puede afirmar que la misma quiebra por el hecho de que sean las zonas con un desarrollo económico mediano, y no las más empobrecidas, las que lideren el ranking de emisores de migraciones internacionales, y también porque los migrantes de países de ingresos bajos residan en mayor medida en Estados de rentas medias. Sin embargo, no existe tal contradicción, es más, abunda en la relevancia de la precaria situación de los países más vulnerables como factor clave en la configuración de la movilidad humana contemporánea. La capacidad de recurrir a la movilidad de forma legal y segura como estrategia personal de lucha contra la vulnerabilidad está supeditada al origen nacional. Esta opción está prácticamente vedada para los nacionales de países de ingresos bajos, que se ven abocados a migrar por vías irregulares e inseguras.

Podemos señalar como ejemplo el Reglamento de la Unión Europea n. ${ }^{\circ}$ 539/2001 del Consejo (15 de marzo de 2001), por el que se establecen la lista de terceros países cuyos nacionales necesitan visado para cruzar las fronteras exteriores y la lista de terceros países cuyos nacionales están liberados de esa obligación. Llama la atención que es muy superior el número de países a los que se les exige visado (103) respecto al de los que están exentos (59). Más revelador es indagar en el perfil de los Estados que se encuentran en este segundo grupo: no hay ninguno calificado como de bajos ingresos en general, y ninguno africano, en particular. Entre los países a los que se les exige visado nos encontramos solo tres que se consideran como de ingresos altos (Arabia Saudí, Bahréin y Kuwait), aunque su inclusión en este grupo se deba a cuestiones vinculadas a la seguridad y a la «lucha contra el terrorismo internacional». Es en este listado donde encontramos el grueso de los países de bajos ingresos. 
Debemos concluir que la voluntad política de la UE, el principal polo de atracción de las migraciones a nivel mundial ${ }^{4}$, es priorizar el acceso a su territorio por vías legales y seguras a las personas nacionales de países de ingresos medios y altos, mientras que estas quedan muy limitadas (o vetadas) para aquéllas que provienen de las zonas empobrecidas. Esta situación no es exclusiva de Europa; se reproduce en otras regiones atractivas para las migraciones, como Estados Unidos. El Visa Waiver Program ${ }^{5}$ del país norteamericano, donde se establece la exención de visado para entrar en su territorio a los nacionales de tan solo 38 países. El programa excluye de ese listado incluso a los países de ingresos medios.

En este contexto político-jurídico cobra su sentido que sean las personas de países de ingresos medios y altos las que mayoritariamente protagonicen la movilidad humana global, y que las personas nacionales de las regiones más empobrecidas migren a zonas con un desarrollo económico mediano, ya que tienen vedado el acceso regular a los países con mayor nivel de desarrollo humano. Y, por ende, podemos reiterar que un ejercicio normalizado de la libertad de circulación acaba siendo un privilegio vinculado a la nacionalidad de determinados Estados, y un síntoma de vulnerabilidad de las personas originarias de las regiones empobrecidas. Esa vulnerabilidad se traduce en que estas últimas tengan que utilizar vías irregulares e inseguras para intentar mejorar sus condiciones de vida.

Baste en estas primeras líneas concluir que, a día de hoy, como a lo largo de la historia, la búsqueda de la mejora de las condiciones de vida continúa siendo el principal motor de la movilidad humana.

En este apartado hemos centrado nuestra atención en las causas de las migraciones vinculadas con las desigualdades económicas, pero estas no son las únicas que generan contextos hostiles al respeto de la dignidad humana. Conflictos bélicos o situaciones de vulneración masiva de derechos humanos por motivos étnicos, religiosos, políticos... también representan un «efecto expulsión» generador de movimientos de población. Aunque ya señalamos que, en la actualidad, los flujos migratorios tienen un marcado carácter mixto, en aras de una mayor claridad

\footnotetext{
${ }^{4}$ De los 28 Estados de la UE, tan sólo Rumanía y Bulgaria no son considerados como de altos ingresos, representando conjuntamente el mayor PIB a nivel global. Datos disponibles en: https://europa.eu/ european-union/about-eu/figures/economy_es

5 Programa gestionado por el Department of Homeland Security del Gobierno de EE.UU. Disponible en: https://www.dhs.gov/visa-waiver-program
} 
expositiva es pertinente dedicar un espacio específico a los conflictos como causa de las migraciones y al derecho de asilo como herramienta políitico-jurídica destinada a su gestión.

\section{Conflictos y contextos de vulneración generalizada de los derechos humanos como factores en las migraciones contem- poráneas: el asilo/refugio}

\section{I. Seguridad humana y conflictos}

En el citado Informe sobre Desarrollo Humano 2014 se hace mención a un concepto de singular significación para la materia que nos ocupa, el de seguridad humana, noción que lleva trabajando el PNUD desde hace 20 años como un aspecto integral del desarrollo humano. Considera que

el conflicto y la sensación de inseguridad personal tienen impactos adversos generalizados en el desarrollo humano y que no es casualidad que muchos países en el nivel más bajo del Índice de Desarrollo Humano están saliendo de largos periodos de conflicto o aún enfrentan violencia armada (PNUD, 2014: 4-5).

Destaca el informe que cerca de una quinta parte de la población mundial ( 1.500 millones de personas) vive en países afectados por conflictos.

Las situaciones de conflicto o de violaciones de derechos humanos generalizadas constituyen por si solas motores de la movilidad humana, siendo relevante el ejemplo que el informe del PNUD destaca respecto a la zona América Latina-Caribe:

en una serie de países de América Latina y el Caribe, a pesar de los altos logros de desarrollo humano, muchas personas se sienten amenazadas por las crecientes tasas de homicidio y otros delitos violentos (PNUD, 2014: 5),

lo que genera importantes desplazamientos de población internos y externos.

En la actualidad, múltiples conflictos abiertos provocan millones de desplazamientos. Dichos conflictos son diversos y muestran la complejidad de esas realidades, aunque se puede concluir que el aumento de la conflictividad determina un correlativo incremento de la movilidad humana. Esta afirmación es contrastable a través de índices que estudian las situaciones de conflicto a nivel global. 
El Global Conflict Risk Index (Comisión Europea), establece un «top 20» entre los países con un mayor riesgo de conflictos (Smidt et al., 2016: 17), teniendo en común los países incluidos en ese listado ser destacados emisores de movimientos migratorios internos y externos: Afganistán, Mali, Pakistán, República Democrática del Congo, Siria, Somalia, Ucrania... Estas circunstancias son corroboradas por otros índices que miden esta dimensión desde la perspectiva contraria, es decir, el "grado de paz y estabilidad». Es lo que mide el Global Peace Index, elaborado por el Institute for Economics and Peace, en el cual comprobamos que los países que ocupan los últimos lugares del ranking tienen una gran incidencia de desplazamientos de población internos y externos (Institute for Economics and Peace, 2016).

\subsection{Las herramientas formales de respuesta a las migraciones provocadas por conflictos y violaciones generalizadas de los Derechos Humanos}

Las herramientas político-jurídicas creadas para dar respuesta a los desafíos que plantea la movilidad humana vinculada a los conflictos y a las situaciones de vulneraciones de derechos humanos generalizadas son los conceptos de refugiado y de derecho de asilo. Fue la Declaración universal de los derechos humanos la que dio carta de naturaleza a dichas herramientas, al establecer en su art. 14.1: «En caso de persecución, toda persona tiene derecho a buscar asilo, y a disfrutar de él, en cualquier país».

La Convención de Ginebra de 1951 y su Protocolo de Nueva York de 1967 dotaron de contenido sustantivo a lo genéricamente reconocido por el art. 14.1 DUDH, estableciendo el concepto de refugiado y el derecho de asilo como los instrumentos para dotar de protección a las personas que cumplan los requisitos para obtener la condición de refugiado. Igualmente, se fueron creando normas en materia de asilo de carácter regional para fortalecer el marco normativo universal, como la Convención relativa a los aspectos propios de los problemas de los refugiados en África (Organización para la Unidad Africana-OUA-1969) o la Declaración de Cartagena sobre Refugiados (Organización de Estados Americanos-OEA-1984).

Pero, es quizás la Unión Europea la que ha desarrollado un entramado normativo regional en materia de asilo más ambicioso. El art. 78.1 del Tratado de Funcionamiento de la UE (TFUE) prevé un sistema común de asilo y el art. 18 de la Carta de Derechos Fundamentales de la Unión Europea (CDFUE) reconoce el derecho

6 Este índice tiene en cuenta variables como situación política, situación económica, conflictividad, seguridad pública, cohesión social y características geográficas/ambientales. 
de asilo en el ámbito de la Unión. Ese reconocimiento formal trata de implementarse a través de los reglamentos de Dublín I y II (reglamentos CE 343/2003 y UE 604/2013) y las directivas 2011/95/UE (por la que se establecen normas relativas a los requisitos para el reconocimiento de nacionales de terceros países o apátridas como beneficiarios de protección internacional, a un estatuto uniforme para los refugiados o para las personas con derecho a protección subsidiaria y al contenido de la protección concedida) 2013/32/UE (sobre procedimientos comunes para la concesión o la retirada de la protección internacional) y 2013/33/UE (por la que se aprueban normas para la acogida de los solicitantes de protección internacional).

\subsection{Desafíos a la efectividad material del sistema internacional de asilo}

A pesar del esfuerzo por crear un Derecho Internacional universal y regional en materia de asilo, coincidimos con Martín Arribas (2000) en que la protección material que da sentido real al concepto de derecho de asilo sigue siendo todavía una cuestión vinculada a la soberanía nacional de los Estados, y ello representa un hándicap para su efectividad.

El informe de ACNUR Tendencias globales. Desplazamiento forzado en 2016 presenta una completa radiografía de la realidad descrita. El documento ofrece cifras que demuestran que la creciente conflictividad global incrementa significativamente los movimientos de población vinculados a conflictos armados o situaciones generalizadas de violación de Derechos Humanos. También ponen de relieve la quiebra del sistema internacional de asilo como herramienta de respuesta a las necesidades de protección que patentizan estos flujos migratorios (ACNUR, 2017). Desde la primera perspectiva, durante el año 2016 el número de personas desplazadas forzosamente en el mundo alcanzaron los 65,6 millones y se formalizaron dos millones de nuevas solicitudes de asilo. En cuanto a los datos de 2016 que muestran la quiebra del sistema, podemos destacar:

- El 84\% de las personas refugiadas se encuentran acogidas en países empobrecidos o de ingresos medios, lo que pone en cuestión la eficacia material de la protección que ofrece la figura del derecho de asilo.

- Apenas 189.000 personas refugiadas fueron reasentadas en Estados con mejores condiciones de vida. Ello es consecuencia de que el derecho de asilo dependa de la soberanía estatal y de la falta de poder vinculante de las organizaciones internacionales competentes en la materia. 
- El número de los retornados superó el medio millón, un incremento respecto a años anteriores vacío de contenido, al dirigirse la mayoría de los retornos a un país como Afganistán (384.000).

- Protagonismo en los desplazamientos forzados de los grupos sociales más vulnerables: las personas menores de edad representan el $51 \%$ de la «población refugiada» mundial. Con los colectivos más débiles es donde la protección que debería ofrecer el sistema internacional de asilo evidencia su fragilidad: EUROPOL dio cuenta en febrero de 2016 de que se había perdido el control sobre unas 10.000 personas menores de edad que habían ingresado en territorio europeo en busca de protección (Parlamento europeo, 2016 y UNICEF, 2016 a).

Las nuevas realidades complejas desbordan a la Convención de Ginebra y su Protocolo, que se muestran faltos de respuestas a las necesidades de protección distintas a las generadas por un conflicto bélico clásico o por la persecución estatal organizada. En este ámbito podemos destacar las situaciones de violencia social en países como Honduras, Guatemala o El Salvador. Desde que surgieron en los albores del siglo XXI, se han producido importantes desplazamientos de población internos y externos como consecuencia de las violaciones de Derechos Humanos vinculadas a fenómenos delincuenciales como las llamadas "maras» y a la falta de capacidad y/o voluntad política para ofrecer una protección adecuada a las capas sociales más vulnerables de su ciudadanía.

En la situación de violencia generalizada en el "Triángulo Norte" centroamericano confluyen factores que no encajan exactamente en las causas de persecución de la Convención de Ginebra, como decisiones de política migratoria de un país tercero ${ }^{7}$, el tráfico de estupefacientes, corrupción política, Estados de Derecho muy débiles, circulación de armas de fuego sin control, largos conflictos armados civiles cerrados en falso... Estos elementos configuran un fuerte "efecto expulsión» para miles de personas de la región, respecto de las cuáles se ha dudado de su condición de verdaderas refugiadas. Incluso cuando se superan las dudas formales iniciales, se encuentran dificultades para brindarles una protección efectiva en el marco del sistema de protección internacional «tradicional» (ACNUR, 2010 y Wolf, 2015).

La "crisis" de los refugiados en Europa es otra de las realidades que muestra como el "sistema Ginebra» no es capaz de dar una respuesta articulada a las demandas de protección derivadas de los conflictos contemporáneos y los nuevos actores polí-

${ }^{7}$ El origen de las maras se sitúa en las deportaciones masivas de jóvenes centroamericanos en situación irregular y con antecedentes penales que llevó a cabo Estados Unidos entre finales de los años 90 y el inicio del presente siglo. 
ticos distintos al Estado nación, como es el caso de la UE (CEAR 2017: 41 y ss.). La gestión, por parte de la Unión Europea, del incremento de personas que demandan protección en sus fronteras ha sido un fracaso político-jurídico y humanitario.

Desde la perspectiva político-jurídica, las instituciones europeas han fallado a la hora de dotarse de unas herramientas ágiles para dar una respuesta respetuosa con el marco internacional de los Derechos Humanos. Dejando a un lado el colapso del incipiente Sistema Europeo Común de Asilo (SECA), las soluciones políticas ad hoc de emergencia que se aprobaron en el seno de la UE en los años 2015 y 2016 han sido muy ineficaces. En septiembre de 2015, los Estados UE se comprometieron a reubicar desde Grecia e Italia a otros países europeos a 160.000 personas refugiadas y a reasentar desde países limítrofes con Siria a unas 22.000. A junio de 2017, la plasmación práctica de esos compromisos apenas llegaba al 16\% (CEAR, 2017: 43). Y como colofón negativo, el acuerdo UE-Turquía para frenar los flujos migratorios que accedían a Grecia desde suelo turco, cuya incompatibilidad con principios básicos del Derecho Internacional de los Derechos Humanos ha generado amplios consensos en el mundo académico y de la sociedad civil (Provera, 2016).

Respecto a las fallas humanitarias, basta señalar que como consecuencia directa o indirecta de dichas políticas durante el año 2015 perdieran la vida en el Mediterráneo intentado alcanzar territorio europeo 3784 personas, incrementándose hasta las 5098 en el año $2016^{8}$.

\section{La libertad de circulación/movilidad humana en el ámbito político-jurídico internacional y su configuración como dere- cho humano}

\section{I. Reconocimiento político-jurídico de la libertad de circulación a nivel internacional}

El nivel de reconocimiento político-jurídico de la libertad de circulación en el ámbito supranacional no se corresponde con el contexto favorable a la movilidad que conlleva la globalización. El control de las fronteras nacionales y la selección de las personas a las que permiten acceder a su territorio son prerrogativas de

${ }^{8}$ Missing Migrant Project. (OIM). Disponible en: http://missingmigrants.iom.int/mediterranean 
las que los Estados-nación son muy refractarios a desprenderse, lo que dificulta la evolución hacia una libertad de circulación global

Lo anterior se plasma en el marco internacional de reconocimiento de la libertad de circulación. A un nivel universal, podemos destacar el art. 13 de la Declaración Universal de los Derechos Humanos (DUDH) y el art. 12 del Pacto Internacional de los Derechos Civiles y Políticos (PIDCP); en el contexto regional, son reseñables el art. 22 de la Convención Americana de los Derechos Humanos (CADH) y el art. 2 del Protocolo $4^{\circ}$ del Convenio Europeo de Derechos Humanos (CEDH).

Sin realizar un análisis exhaustivo de dichas normas, se pueden obtener unas sumarias conclusiones de la simple lectura de las mismas:

a) Se reconoce la libertad circulación interna (dentro de las fronteras de un Estado), incluyendo la fijación de domicilio. El art. 13 DUDH la contempla sin restricciones (toda persona), algo que es matizado por PIDCP, CADH y CEDH, que exigen situación legal en el territorio del Estado de que se trate, lo que conlleva el cumplimiento de las normas nacionales de "extranjería" en el caso de personas migrantes.

b) Se reconoce una libertad de circulación externa (la que implica traspasar fronteras) más restringida que la interna. Estas declaraciones consagran el derecho de salir de cualquier país, incluso del propio. Desde el punto de vista subjetivo no se hace restricción respecto a la nacionalidad o situación legal. Es en el contenido material donde encontramos limitaciones que cuestionan la virtualidad práctica de esta dimensión de la libertad de circulación:

* El art. 13.2 DUDH incluye como parte de la misma el derecho a regresar al país propio, a diferencia del resto de instrumentos internacionales. Se puede sostener que la referencia al derecho de abandonar el país propio implica la posibilidad del regreso, aunque ello se situaría en el terreno de las interpretaciones de segundo grado.

* Pero, lo que realmente pone en el alero la materialidad de la libertad de circulación externa, es que el "derecho a salir» libre y universal no se ve correspondido por un «derecho a entrar» con las mismas características. Este último queda en manos de las políticas nacionales migratorias y de fronteras, y por ende condicionado a los intereses de cada Estado.

Es opinión académica y político-jurídica consolidada que el «derecho a dejar cualquier país, incluso el propio» es un derecho humano universal. En este sentido es interesante el documento The right to leave a country del Comisionado de Derechos 
Humanos del Consejo de Europa (Guild, 2013), que analiza el reconocimiento del mismo en el Derecho Internacional y la jurisprudencia «supranacional» sobre la materia. El informe destaca que políticas como la "externalización de fronteras» de la UE y sus Estados pueden considerarse como un ataque al derecho a dejar libremente cualquier país, incluso el propio (Guild, 2013: 53 y ss).

\subsection{La libertad de circulación en los procesos de integración política regional}

Los procesos de integración regional han tenido una especial incidencia en materia de libertad de circulación. Aunque, inicialmente, estos procesos priorizaban la libre circulación de mercancías y capitales, conforme se consolidaba la de personas, también acabó apareciendo entre sus objetivos.

Es en la Unión Europea donde se ha llevado a cabo un mayor desarrollo de la libre circulación de personas a un nivel regional. La Carta de Derechos Fundamentales de la UE -CDFUE- (art. 45) la consagra como derecho fundamental vinculado a la ciudadanía europea, y abre la posibilidad de extenderlo a personas extranjeras que residan legalmente en la Unión. Se considera como una piedra angular del proyecto europeo desde el Tratado de Maastricht de 1992'. No ha sido un proceso pacífico la instauración de un espacio europeo de libre circulación. La ampliación hacia a los países del Este, la alarma social generada por el terrorismo internacional o el auge de los populismos nacionalistas al abrigo de la crisis han puesto en el punto de mira esta cuestión.

En el Mercosur ${ }^{10}$ también se han dado pasos en el objetivo de una libertad de circulación regional, aunque se encuentra en una fase embrionaria. El Estatuto de la Ciudadanía ${ }^{11}(2010)$ establece en su art. 2 como objetivo estratégico la «implementación de una política de la libre circulación de personas en la región». En el acervo normativo de Mercosur se han incorporado normas que permiten viajar a

9 La libertad de circulación también se desarrolla en el art. 3.2 del Tratado de la Unión Europea (TUE); art. 21 y títulos IV y V del Tratado de Funcionamiento de la Unión Europea (TFUE) y la Directiva 2004/38/CE. A través del Acuerdo de Schengen la libre circulación se extiende a algunos países europeos que no pertenecen a la UE (Islandia, Liechtenstein, Noruega y Suiza).

10 Organización de integración latinoamericana a la que pertenecen Argentina, Brasil, Paraguay, Uruguay y Venezuela. Bolivia se encuentra en periodo de adhesión y Mercosur también mantiene acuerdos de asociación con otros países de la región.

${ }^{11}$ Decisión 64/10 del Consejo del Mercado Común de Mercosur. 
los nacionales de los Estados miembro y de algunos asociados por el territorio del Mercosur sin visado y utilizando documentos de identidad nacionales, y facilitan el acceso a la residencia legal a dichos nacionales en estos Estados ${ }^{12}$.

Siendo avances significativos, no constituyen un verdadero espacio de libre circulación, especialmente en lo concerniente a la residencia legal, que se sigue moviendo en los parámetros de la gestión migratoria estándar. También es asimétrico este espacio en cuanto a los países que efectivamente forman parte de él, debido a que varían los Estados miembro y asociados que han firmado los acuerdos que lo configuran.

Para concluir, una breve referencia al Sistema de Integración Centroamericano (SICA), proceso de integración del que forman parte la mayoría de los países del Istmo ${ }^{13}$ (Caldentey y Romero, 2010). Dentro de los objetivos generales del SICA no se incluye establecer una libre circulación de personas regional ${ }^{14}$. Es significativo que las funciones relacionadas con la libertad de circulación se asignen a un órgano subsidiario del sistema con competencias sectoriales, el Consejo Centroamericano de Turismo (CCT), que debe «tratar de eliminar todos los obstáculos e impedimentos al libre movimiento de personas de la región».

Se pueden destacar algunos instrumentos que han constituido una zona de libre circulación entre El Salvador, Honduras, Guatemala y Nicaragua ${ }^{15}$, tanto para sus nacionales como para algunas categorías de personas de terceros países. Siendo un paso interesante, el hecho de que se extienda sólo a cuatro Estados miembros (revelador que Costa Rica, país con mayor índice de desarrollo humano de la región, sea el más refractario a los avances en esta materia) y la propia debilidad institucional del SICA pone en cuestión su alcance real.

\footnotetext{
${ }^{12}$ Acuerdos sobre Documentos de Viaje de los Estados Partes del Mercosur y de los Estados Asociados de 2008 y 2014, Decisiones CMC 28/02, 04/11, 21/11 y 20/12, Acuerdo sobre Residencia para los Nacionales de los Estados Partes del Mercosur y Acuerdo sobre Residencia para los Nacionales de los Estados Partes del Mercosur, Bolivia y Chile.

${ }^{13}$ Belice, Costa Rica, El Salvador, Guatemala, Honduras y Nicaragua, a los que se une la caribeña República Dominicana.

${ }^{14}$ Ver arts. 2 y 3 del Protocolo de Tegucigalpa de 1991, carta fundacional del SICA.

${ }^{15}$ Acuerdo de Nueva Ocotepeque (1992), Acuerdo de Managua (1993) y Convenio de creación de la Visa Única Centroamericana para la libre movilidad de extranjeros (2005).
} 


\subsection{Ciudadanía, libertad de circulación y movilidad humana}

Desde las revoluciones liberales, el concepto de ciudadanía en el marco del estadonación se ha erigido como la principal herramienta político-jurídica de titularidad y ejercicio de derechos fundamentales (Arce, 2009: 23). La transición del súbdito al ciudadano marcó un hito e impulsó la construcción de la teoría políitico-jurídica moderna de los derechos que culminaría con la DUDH.

Sin embargo, el concepto de ciudadanía siempre ha navegado en la tensión de dos tendencias de inclusión y exclusión, consecuencia de la diferenciación entre personas ciudadanas y no ciudadanas. Solo los que ostentan una ciudadanía plena tendrán una titularidad y ejercicio de sus derechos fundamentales igualmente plenos. Diferentes han sido a lo largo de la Historia las situaciones que han privado del acceso a la ciudadanía plena a ciertos colectivos sociales: género, raza, religión, status socioeconómico y nacionalidad.

El concepto de ciudadanía ha llevado a cabo un proceso inclusivo que ha suprimido los obstáculos formales que impedían el acceso a la titularidad y ejercicio de sus derechos sin restricciones. Tan sólo uno se mantuvo: la necesidad de ostentar la nacionalidad del Estado de que se trate (Arce, 2012: 322 y ss).

El impacto de esa exclusión se ha agudizado con el incremento de la movilidad humana transnacional. Cada vez son más las comunidades de personas extranjeras en los principales países de destino y tránsito de los flujos migratorios, y el hecho de no tener reconocida la ciudadanía plena conlleva graves situaciones de exclusión para ellas (Arce, 2009: 20 y ss).

No puede sostenerse que las personas no ciudadanas estén despojadas de cualquier derecho en el marco del sistema internacional de los derechos humanos. De hecho, el DIDH tiene como base el concepto de dignidad humana, de la que es titular todo ser humano independientemente de cualquier circunstancia personal, política o jurídica, por lo que se le debe respetar un mínimo de derechos independientemente de la nacionalidad que ostente y el Estado donde resida. El Alto Comisionado de las Naciones Unidas para los derechos humanos (ACNUDH), en su documento Los derechos de los no ciudadanos (ACNUDH, 2006) realiza una relación de esos derechos, sus titulares y condiciones de ejercicio. De este informe se pueden obtener algunas conclusiones de interés:

a) Existe una cierta contradicción entre el principio general de igualdad de los no ciudadanos vinculado a la dignidad humana (ACNUDH, 2006: 9 y ss.), con 
la afirmación de que existen diferentes categorías de personas no ciudadanas y que es lícito que se le apliquen distintos regímenes de derechos según su estatus jurídico-administrativo (ACNUDH, 2006: 5 y ss.). La categorización de personas en materia de derechos es difícilmente compatible con el principio de igualdad.

b) El catálogo de derechos que se definen como específicos de los no ciudadanos destaca por ser escueto, sobre todo en materia de derechos políticos, sociales y económicos (ACNUDH, 2006: 17 y ss.).

c) Es destacable la contundente afirmación que realiza el documento al tratar la libertad de circulación: Las personas no tienen derecho a entrar o residir en los países de los que no son ciudadanos (ACNUDH, 2006: 20), haciendo alusión a jurisprudencia del Tribunal Europeo de los Derechos Humanos como apoyo a la misma. Consideramos que es una muestra de las limitaciones de base de la libertad de circulación que se configuró a partir del art. $13 \mathrm{DUDH}$, lo que, junto a la vinculación que persiste entre ciudadanía plena y nacionalidad, determinan un contexto político-jurídico que no da respuesta a los desafíos de la movilidad humana contemporánea.

Una de las alternativas que se han alentado para dar respuesta a esos retos es un concepto de ciudadanía que supere las fronteras estatales para poder seguir siendo un eficaz instrumento de titularidad y ejercicio de derechos fundamentales. En esta línea el proyecto de ciudadanía transnacional más avanzado es el de la ciudadanía europea.

Dado que no es el lugar para realizar un extenso análisis de la realidad políticojurídica que representa la ciudadanía europea (Arce, 2012: 103 y ss), baste con destacar que representa un hito que derechos como la libertad de circulación (art. 45 CDFUE), y derechos políticos como el sufragio pasivo y activo en elecciones europeas y municipales (arts. 39 y 40 CDFUE), superen el vínculo exclusivo de la nacionalidad estatal dentro del territorio de un Estado-nación. Ostentan la ciudadanía europea las personas que sean nacionales de un Estado miembro, que podrán ejercer los derechos a ella anudados independientemente del Estado UE en el que residan (arts. 9 TUE y 20 TFUE). Reconociendo su carácter pionero, la ciudadanía europea dista aún de poder considerarse una ciudadanía transnacional que represente una alternativa real a la nacional, más si cabe si se tiene en cuenta la etapa de incertidumbre en la que se encuentra el proyecto de integración europea desde el estallido de la crisis global que ha afectado singularmente a la UE. 
Ya aludimos a la existencia de otra iniciativa de construcción de una ciudadanía supranacional en el marco de Mercosur, donde en el año 2010 se aprobó un Estatuto de la Ciudadanía de Mercosur, que no deja de ser más un plan de acción política que una realidad jurídica consolidada. Guarda similitudes con la ciudanía europea, ya que en su art. 2 el Estatuto también circunscribe el acceso a la misma a los nacionales de los Estados miembros, y determina que su contenido material se centrará en la libertad de circulación y en la igualdad de trato en materia de derechos civiles y socioeconómicos. Esta propuesta se encuentra en un estado inicial, dado el escaso tiempo transcurrido desde la aprobación de este plan de acción y que el propio proyecto de Mercosur está en una fase desarrollo muy inferior respecto a la UE.

\section{Vulneraciones de derechos humanos en los flujos migrato- rios en tránsito y en frontera}

Hemos comprobado que existe una grave disfunción entre la movilidad humana característica de la era de la globalización y las herramientas político-jurídicas disponibles para encauzarla de una forma legal, ordenada y segura. La principal consecuencia del desajuste es que gran parte de los flujos migratorios se vean obligados a utilizar vías irregulares e inseguras, que tienen un alto costo en forma de violaciones de derechos humanos (que se concentran especialmente en las zonas de tránsito de las migraciones y en las fronteras). Estas circunstancias afectan a las poblaciones más vulnerables procedentes de las zonas empobrecidas del planeta, que son aquellas a las que se les cierra de una forma más contundente el acceso legal y seguro a los principales países de destino.

Ya constatamos que la movilidad humana es más intensa entre los países de ingresos medios y altos, siendo menos numerosos los flujos migratorios entre regiones de ingresos bajos y medios e inferiores aún entre las más empobrecidas y las que disfrutan de un mayor bienestar (ONU, 2016). Sin embargo, las vulneraciones de derechos humanos acontecen mayoritariamente en estos dos últimos corredores, ya que en ellos brillan por su ausencia las vías legales y seguras para ejercer la libertad de circulación.

Existen diversas zonas de tránsito de migraciones internacionales y fronteras donde el respeto a los derechos fundamentales es muy precario. Y ello, a pesar de que el DIDH trata de establecer un marco mínimo para evitar esas situaciones proclamando principios como: 
- Principio de no devolución. Prohíbe devolver a una persona a un país donde haya riesgo fundado de sufrir violaciones de sus derechos básicos, aunque haya accedido de forma irregular al territorio del que va a ser expulsado o no cumpla los requisitos para ser acreedor de protección internacional (art. 3 de la Convención contra la Tortura y Otros Tratos o Penas Crueles, Inhumanos o Degradantes, art. 33.1 de la Convención sobre el Estatuto de los Refugiados...).

- Prohibición de expulsiones arbitrarias y colectivas (art. 22 Convención internacional sobre la Protección de los Derechos de todos los Trabajadores Migratorios y de sus Familiares, art. 4 del Protocolo N. ${ }^{\circ} 4$ del Convenio Europeo de Derechos Humanos, art. 22.9 Convención Americana de los Derechos Humanos...).

- Garantía de acceso al procedimiento de asilo (art. 18 Carta de Derechos Fundamentales de la Unión Europea, art. 22.7 Convención Americana de los Derechos Humanos...).

- El resto de derechos humanos elementales como el derecho a la vida, la integridad física, tutela judicial efectiva... no tienen un régimen excepcional en situaciones de tránsito migratorio o de frontera. Por ende, la titularidad y ejercicio de los mismos por parte de las personas migrantes en esos contextos no deben sufrir limitaciones.

Ese marco de protección se revela como insuficiente para garantizar la indemnidad de las personas migrantes en tránsito y en frontera. Dentro de los corredores migratorios del planeta, podemos destacar dos por la gravedad de las vulneraciones de los derechos humanos que se han documentado en los mismos.

\section{I. El triángulo Europa, Norte de África y Oriente Próximo}

Europa pasó de ser una región emisora de migraciones durante siglos a convertirse en un territorio de acogida con la reconstrucción socioeconómica iniciada tras la $2^{a}$ Guerra Mundial, y posteriormente con la globalización. De hecho, es la zona del planeta con un mayor número de migrantes transnacionales, alcanzando en 2015 los 76 millones (ONU, 2016).

A pesar de lo anterior, las políticas europeas (de la UE y de sus Estados miembro) migratorias y de fronteras se han mostrado ineficaces a la hora de garantizar la indemnidad de los derechos humanos de las personas migrantes. La dimensión de los efectos de dichas políticas se puede calibrar a través de una cifra: en el periodo 1993-2014, cerca de 30.000 personas perdieron la vida en las fronteras euro- 
peas $^{16}$. Las vías de acceso a Europa se han tornado inseguras y transformado en un negocio para las organizaciones que se lucran con las migraciones irregulares, contra las que, según el discurso oficial, se dirigen prioritariamente las estrategias de control de migraciones y fronteras de la UE y sus Estados miembros.

Esta situación se ha visto agravada en el contexto de la "crisis" de los refugiados. En este escenario emerge el concepto de flujos mixtos (OIM, 2009), ya sea porque en él se integran colectivos que encajan en el concepto formal de persona refugiada con otros que no, como porque en las motivaciones individuales de cada persona migrante se entremezclan elementos propios de dicho concepto con otros diferentes. Durante el año 2015, más de un millón de personas arribó a suelo europeo (OIM, 2016). El incremento de llegadas ha traído un aumento del coste en vidas humanas: en el año 2015 perdieron la vida en el Mediterráneo intentado alcanzar territorio europeo 3784 personas, totalizando 5098 personas en 2016, a pesar de haberse reducido el número de entradas respecto al año anterior ${ }^{17}$.

No faltan voces desde la sociedad civil y las instituciones que critican con contundencia las consecuencias de estas políticas. Entre las primeras destaca el informe anual de la ONG española Asociación Pro Derechos Humanos de Andalucía (APDHA) Derechos Humanos en la Frontera Sur, donde se analizan las violaciones de los derechos básicos de las personas migrantes que se producen en las frontera euroafricana y euroasiática (APDHA, 2017). En el ámbito institucional nos parece significativo que un organismo de la propia UE (su Agencia para los Derechos Fundamentales -FRA-) publicara en 2013 un informe muy crítico con la gestión europea en esta materia (FRA, 2013).

Una de las principales estrategias de control de flujos migratorios irregulares de la Unión y los Estados europeos es la "externalización del control de fronteras». La externalización consiste en trasladar a terceros países la responsabilidad de controlar las migraciones irregulares, países que no destacan precisamente por sus altos estándares en materia de derechos humanos (Marruecos, Turquía. Libia...), y que reciben a cambio relaciones político-económicas más favorables con la UE. En este sentido es llamativo cómo las políticas europeas de cooperación al desarrollo con países africanos emisores o de tránsito de personas migrantes se condicionan a su implicación en el control migratorio (Azkona, 2013). También

\footnotetext{
${ }^{16}$ Datos de United for Intercultural Action (Proyecto Migrants Files). Disponible en: http://www.themigrantsfiles.com/

17 Datos obtenidos del Missing Migrant Project (OIM). https://missingmigrants.iom.int/mediterranean
} 
podemos encuadrar en la externalización de fronteras el citado acuerdo UE-Turquía, con el agravante de que en este caso su aplicación afecta a personas que en un principio cumplen todos los requisitos para que se les pueda reconocer el estatuto de refugiado.

\subsection{El corredor centroamericano}

Otra de las zonas calientes migratorias del planeta es el corredor centroamericano. Al igual que ocurre en las fronteras euroafricana y euroasiática, las desigualdades de desarrollo humano unidas a la cercanía geográfica configuran un contexto donde la movilidad de poblaciones es inevitable.

Según datos de la US Border Patrol ${ }^{18}$, en los últimos 5 años el número de personas migrantes detenidas por acceder irregularmente a territorio estadounidense ha oscilado entre los 331.333 del año 2015 y los 479.371 del año 2014. En el año 2016 se experimentó un nuevo incremento de las llegadas (415.816). Estas cifras están lejos de los 1,6 millones del año 2000 y también del millón que arribaron a suelo europeo durante 2015, pero aún siguen siendo significativas a nivel global.

Tampoco existen en esta zona del planeta vías legales y seguras de acceso a territorio norteamericano ${ }^{19}$, y ello fomenta la vulneración de derechos fundamentales de las personas migrantes en tránsito y frontera. Según la OIM, en 2016 perdieron la vida 398 personas intentando entrar a Estados Unidos (422 en el año 2015) ${ }^{20}$. Aunque son cifras inferiores a las del Mediterráneo, no deja de ser una situación intolerable. Las vulneraciones de derechos humanos que sufren las personas migrantes centroamericanas en tránsito por México han sido motivo de preocupación para la sociedad civil y las instituciones internacionales (Guadagno y Hernández-Ardieta, 2016).

Una realidad en la frontera sur estadounidense que ejemplifica la vulnerabilidad vinculada con la pobreza, la violencia y las migraciones es la de los menores

\footnotetext{
${ }^{18}$ Hay que tener en cuenta que esta institución toma como referencia temporal el "año fiscal" (desde el 1 de octubre hasta el 30 de septiembre del año siguiente). Disponible en: https://www.cbp.gov/sites/ default/files/assets/documents/2016-Oct/BP\%20Total\%20Apps\%2C\%20Mexico\%2C\%20OTM\%20 FY2000-FY2016.pdf

${ }^{19}$ El citado Visa Waiver Program de Estados Unidos no incluye a ninguno de los países centroamericanos.

${ }^{20}$ OIM. Disponible en: https://missingmigrants.iom.int/latest-global-figures
} 
centroamericanos que migran solos huyendo de la situación de violencia generalizada en Guatemala, Honduras y El Salvador. El crimen organizado ejerce una especial presión sobre niños y niñas de los países del Triángulo Norte, con singular incidencia las "maras». Dichas estructuras criminales realizan una estrategia de reclutamiento forzoso de menores de las clases populares; la negativa a incorporarse a las maras o la deserción es equiparable a una sentencia de muerte, lo que impulsa a estos menores a lanzarse solos a un periplo migratorio hacia Estados Unidos, donde en ocasiones ya tienen algún referente familiar.

Las cifras de menores migrantes no acompañados que han alcanzado la frontera Sur estadounidense son alarmantes: de los 24.403 del año 2012 se pasó a los 68.541 de $2014^{21}$. Aunque en 2015 se registró un descenso, en 2016 repuntaron las llegadas (59.757)22. Es evidente la vulnerabilidad en la que se encuentran los menores que realizan su periplo migratorio sin la protección de un adulto por una de las zonas de tránsito de migraciones más peligrosas del planeta. Las organizaciones internacionales humanitarias y de protección de la infancia vienen realizando llamamientos para que los Estados implicados tomen medidas urgentes para garantizar los derechos básicos de estos menores (Camargo, 2014 y UNICEF, 2016 a).

\section{A modo de reflexión final}

Se puede concluir que las migraciones contemporáneas están más vinculadas al concepto de vulnerabilidad que a una titularidad y ejercicio normalizado de los derechos fundamentales de las personas migrantes. Y ello es paradójico en una etapa histórica donde los avances tecnológicos y la transnacionalización de las relaciones humanas deberían dibujar un escenario propicio para la movilidad humana.

La realidad descrita se fundamenta en la ausencia de una estructura político-jurídica que cree vías legales y seguras para la movilidad humana. El origen último de esta disfuncionalidad es la configuración original de la libertad de circulación como

\footnotetext{
21 US Border Patrol. Disponible en: https://www.cbp.gov/newsroom/stats/southwest-borderunaccompanied-children/fy-2016

22 US Border Patrol. Disponible en: https://www.cbp.gov/sites/default/files/assets/documents/2017Jan/USBP\%20Stats\%20FY2016\%20sector\%20profile.pdf
} 
derecho humano. El carácter parcial del reconocimiento de la misma en el art. 13.2 DUDH y en el resto de instrumentos internacionales determina que generar las condiciones para un ejercicio de la movilidad humana compatible con la dignidad de la persona queda al albur de intereses de los Estados, algunas organizaciones internacionales e incluso de agentes económicos privados. $Y$ ese contexto se ha mostrado como terreno hostil para los derechos humanos.

Desde la sociedad civil, la academia y las instancias políticas nacionales e internacionales, se debe afrontar el reto de crear vías legales y seguras para un ejercicio de la libertad de circulación compatible con el respeto a la dignidad humana. Para ello es imprescindible un concepto de movilidad que rompa el estrecho marco del derecho a salir del propio país que se deriva del art.13.2 DUDH. La solución más directa sería una modificación de los pilares de ese marco: art. 13.2 DUDH, art. 12 PIDCP..., aunque el contexto político-jurídico global hace que una iniciativa de este perfil sea poco viable. Sin embargo, a día hoy existen herramientas jurídicas y políticas que podrían ser útiles para conseguir un ejercicio de la movilidad humana respetuoso con los derechos humanos. Apuntamos algunas iniciativas en este sentido:

a) Supresión de las trabas a la movilidad humana por razones humanitarias. El derecho de asilo y los principios básicos de DIDH vinculados a la protección internacional representan un arsenal político-jurídico suficiente para garantizar esta dimensión. Situaciones como las generadas por el acuerdo UE-Turquía son incompatibles con la Convención de Ginebra y susceptibles de ser llevadas ante instancias jurisdiccionales internacionales. El hecho de que siga en manos de los Estados el reconocimiento efectivo de la condición de refugiado y la garantía de los derechos a ella vinculados constituye un hándicap para su efectividad material. Puede ser una línea de avance el desarrollo de instrumentos regionales que hagan trascender dicho reconocimiento y garantía del nivel nacional, tal como tímidamente trata de impulsar la UE con el SECA. La flexibilización del concepto formal de refugiado para adaptarlo a las nuevas necesidades de protección internacional puede coadyuvar a la mejora de la movilidad humana por razones humanitarias.

b) Habilitar vías legales y seguras para unos flujos migratorios ordenados y flexibles. Actualmente, el acceso al territorio de los principales países de destino está vedado a las poblaciones más vulnerables, las más necesitadas de una libertad de circulación realmente efectiva, lo que determina que un alto porcentaje de las migraciones se desarrollen por medios irregulares e inseguros. Estrategias como la "externalización" de fronteras europeas o la cooperación al desarrollo 
condicionada al control migratorio son incompatibles con principios básicos del DIDH, y su supresión es imprescindible. La perspectiva histórica demuestra que la movilidad humana tiene un fuerte componente de autorregulación, y que el facilitar el acceso legal y seguro a los países de destino no generaría «efectos llamada» incontrolados, siendo el medio más eficaz para proteger los derechos humanos de las personas migrantes y combatir la trata de personas. Reforzar el concepto de flujos mixtos facilitaría herramientas intermedias entre la figura clásica de refugiado y la del migrante económico que ayudarían a soslayar disfuncionalidades en esta materia (siguiendo el camino abierto por la figura de la protección internacional subsidiaria).

c) Seguir construyendo espacios de libre circulación vinculados a las propuestas de ciudadanía supranacional de algunos procesos de integración política. La libertad de circulación vinculada a la ciudadanía europea o la que se pretende impulsar con la ciudadanía de Mercosur son experiencias positivas a consolidar, ampliar y "exportar". Generan espacios favorables a la movilidad humana mediante la supresión de controles fronterizos en un ámbito supranacional, y también plantean un nuevo concepto de ciudadanía que tratar de superar los límites que representan para la titularidad y ejercicio de los derechos fundamentales el Estado-nación y la vinculación ciudadanía-nacionalidad.

\section{Referencias}

Agencia para los Derechos Fundamentales de la Unión Europea -FRA- (2013) Fundamental rights at Europe's southern sea borders. Luxemburgo. Disponible en: http://fra.europa.eu/sites/default/files/fundamental-rights-europes-southernsea-borders-jul-13_en.pdf

Alto Comisionado de las Naciones Unidas para los Derechos Humanos -ACNudH(2006) Los derechos de los no ciudadanos. Nueva York y Ginebra. Disponible en: http://www.acnur.org/ $\$ 3 /$ fileadmin/scripts/doc.php?file=ł3/fileadmin/ Documentos/Publicaciones/2008/6561

Alto Comisionado de las Naciones Unidas para los Refugiados -ACNUR- (2010) Nota de orientación sobre las solicitudes de la condición de refugiado relacionadas con las víctimas de pandillas organizada. Ginebra. Disponible en: http://www.acnur.org/ †3/fileadmin/scripts/doc.php?file=\$3/fileadmin/Documentos/BDL/2010/7786 
-(2017) Tendencias globales. Desplazamiento forzado en 2016. Ginebra. Disponible en: http://www.acnur.es/PDF/Tendencias2016.pdf

Amargo, A. (2014) Arrancados de raíz. Causas que originan el desplazamiento transfronterizo de niños, niñas y adolescentes no acompañados y/o separados de Centroamérica y su necesidad de protección internacional. Ciudad de México. Alto Comisionado de Naciones Unidas para los Refugiados. Disponible en: http:// www.acnur.org/ $/ 3 /$ fileadmin/scripts/doc.php?file=ł3/fileadmin/Documentos/ Publicaciones/2014/9828

ARCE, C. (2009) La ciudadanía en la era de la globalización. El reto de la inclusión. Madrid. Editorial Ramón Areces.

-(2012) Los derechos políticos de los residentes extranjeros. La ciudadanía inclusiva. Sevilla. Defensor del Pueblo Andaluz.

Asociación Pro Derechos Humanos de Andalucía -APDHA- (2017) Derechos Humanos en la Frontera Sur 2017. Sevilla. Disponible en: http://www.apdha.org/ media/informe-frontera-sur-2017-web.pdf

Azkona, N. (2013) El II Plan África o cómo continuar con las políticas de externalización de la frontera sur europea y de instrumentalización de la AOD española. Santander. REEDES. Disponible en: http://www.uhu.es/IICIED/pdf/10_5_ii_pla.pdf

CALDENTEY, P. y ROMERO, J. J. (eds.) (2010) El SICA y la UE: la integración regional en una perspectiva comparada. Córdoba. Fundación ETEA para la Cooperación y el Desarrollo.

Comisión ESPAÑOLA DE AYUDA AL REFUGIADO-CEAR-(2017) Informe 2017: Las personas refugiadas en España y en Europa Madrid. Disponible en: https://www.cear.es/ wp-content/uploads/2017/06/Informe-Anual-CEAR-2017.pdf

Fondo de las Naciones Unidas para la Infancia -UNICEF- (2016a) Ayuda refugiados: 10.000 niños desaparecidos en Europa 20/02/2016. Disponible en: http://www.unicef.es/actualidad-documentacion/blog/ ayuda-refugiados-10000-ninos-desaparecen-en-europa

-(2016b) Sueños rotos: El peligroso viaje de los niños centroamericanos a los Estados Unidos. Nueva York. Disponible en: https://www.unicef.es/sites/www. unicef.es/files/unicef_child_alert_central_america_2016_es.pdf 
Guadagno, L. y Hernández-Ardieta, I. (coord..) (2016) Migrantes en México. Vulnerabilidad y riesgos. Ginebra. Organización Internacional de las Migraciones. Disponible en: http://publications.iom.int/es/system/files/pdf/micic_mexico_1.pdf

GuIL, E. (2013) The right to leave a country. Estrasburgo. Consejo de Europa. Disponible en: http://www.coe.int/t/commissioner/source/prems/prems150813_ GBR_1700_TheRightToLeaveACountry_web.pdf

Institute for Economics and Peace (2016) Global Peace Index 2016. Sidney. Disponible en: http://economicsandpeace.org/wp-content/uploads/2016/06/ GPI-2016-Report_2.pdf

MARTín, J. J. (2000) Los estados europeos frente al desafío de los refugiados y el derecho de asilo, Madrid, Dykinson.

ORGANIZACIÓNINTERNACIONALDELAS MIGRACIONES-OIM-(2009) Migraciónirregularyflujos migratorios mixtos: Enfoque de la OIM. Ginebra. Disponible en: https://www.iom.int/ jahia/webdav/site/myjahiasite/shared/shared/mainsite/policy_and_research/ policy_documents/MC-INF-297-Flujos-Migratorios-Mixtos_ES.pdf

-(2016) Mixed Migrations Flows in the Mediterranean and Beyond, Ginebra. http://doe.iom.int/docs/Mixed\%20Migration\%20WEEKLY\%20Flows\%20Compilation_No_\%201_14_January_2016.pdf

ORGANIZACIÓN DE LAS NACIONES UNIDAS -ONU- (2016) International migration report 2015. Nueva York. División de Población del Departamento de Asuntos Económicos y Sociales de Naciones Unidas. Disponible en: http://www.un.org/en/ development/desa/population/migration/publications/migrationreport/docs/ MigrationReport2015_Highlights.pdf

Programa de las Naciones Unidas para el Desarrollo -PNUD- (2014) Informe sobre Desarrollo Humano 2014. Sostener el progreso humano: reducir vulnerabilidades y construir resiliencia. Nueva York. Programa de Naciones Unidas para el Desarrollo. Disponible en: http://www.undp.org/content/dam/undp/library/corporate/ HDR/2014HDR/HDR-2014-Spanish.pdf

Parlamento eUROPEO (2016) 10.000 niños refugiados y migrantes desaparecidos. 20-02-2016. Disponible en: http://www.europarl.europa.eu/news/es/newsroom/20160419STO23927/10.000-ni\%C3\%B los-refugiados-y-migrantesdesaparecidos 
Provera, M. (2016) The UE-Turkey deal. Analysis and Considerations. Bruselas. Servicio Jesuita a Refugiados de Europa. Disponible en: https://irseurope.org/ assets/Regions/EUR/media/files/JRS_Europe_EU_Turkey_Deal_policy_analysis_2016-04-30.pdf

Smidt, M., Vernaccini, L., Hachemer, P. y de Groeve, T. (2016) The Global Conflict Risk Index (GCRI): Manual for data management and productoutput. Italia. Unión Europea. Disponibleen: http://conflictrisk.jrc.ec.europa.eu/Downloads/report_v2.2.pdf

Wolf, S. (2015) Los nuevos refugiados de Centroamérica. Revista Foreign Affairs Latinoamérica. 03-09-2015. Disponible en: http://revistafal.com/ los-nuevos-refugiados-de-centroamerica/
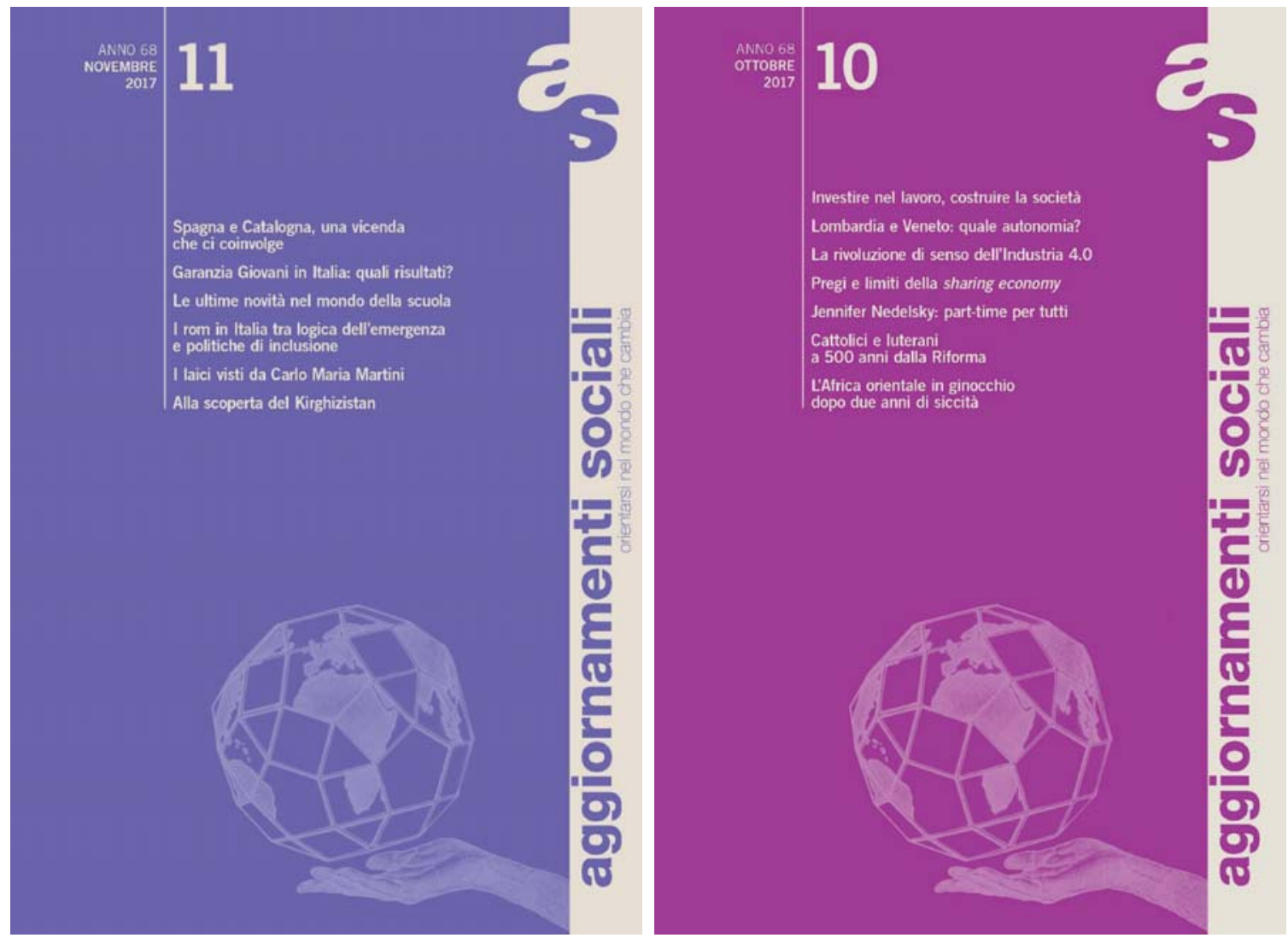